\title{
Determinação de variáveis bioquímicas em eqüinos antes e após a participação em prova de enduro
}

\author{
Biochemical parameters in horses before and after \\ endurance competition
}

Carla Braga Martins, ${ }^{*}$ Cesar Andrey Galindo Orozco, ${ }^{*}$ Flora Helena Freitas D'Angelis, ${ }^{*}$ Eduardo Villela Villaça Freitas, ${ }^{*}$ Fabiana Garcia Christovão, ${ }^{*}$ Antonio de Queiroz Neto, ${ }^{* *}$ José Corrêa de Lacerda Neto***

\begin{abstract}
Resumo
Doze fêmeas eqüinas sadias foram introduzidas em programa de treinamento físico com seis semanas de duração, para participação em provas de enduro na FCAV - UNESP/Jaboticabal. Ao final do período de treinamento, foi realizado um exercício teste (ET), num percurso de $40 \mathrm{~km}$ de extensão. Foram coletadas amostras de sangue para a determinação sérica de proteínas totais, albumina, uréia, creatinina, sódio, potássio, creatina quinase (CK) e aspartato aminotransferase (AST) e plasmáticas de glicose, amônia e fibrinogênio, antes e imediatamente após a prova, assim como 0,5; 6; 24 e 48 horas após. Foram registradas elevações na concentração de amônia, proteínas totais e CK, e diminuição na concentração de potássio. As outras variáveis bioquímicas analisadas não mostraram alterações significativas no decorrer e ao final do ET. As variáveis bioquímicas estudadas apresentaram valores dentro dos limites fisiológicos para a espécie eqüina durante e após o término do percurso, indicando que o teste de esforço realizado não foi capaz de determinar fadiga nesses animais.
\end{abstract}

Palavras-chave: bioquímica sangüínea, eqüinos.

\begin{abstract}
Twelve healthy equine females were introduced in a six-week physical training program for participation in endurance competition at FCAV - UNESP/Jaboticabal. Biochemical parameters were measured in horses submitted to $40 \mathrm{~km}$ way contest. Blood samples were collect to determine serum concentrations of total proteins, albumin, urea, creatinine, sodium, potassium, creatine kinase and aspartate aminotransferase and the plasma concentrations of glucose and ammonia before and after of competition at 0,$5 ; 6 ; 24$ e 48 hour later. An increase of total proteins, creatine kinase, ammonia and fibrinogen concentrations were observed, as well as, a decrease in potassium concentration. Other biochemical parameters showed no significant changes during and after the test period. Values biochemical parameters studied presented were within equine physiological range during and after the competition so that test exercise was not able do determine tined ness in these animals.
\end{abstract}

Keywords: blood biochemistry, equines.

\section{Introdução}

O enduro eqüestre constitui uma importante modalidade de esporte hípico, apresentando um vertiginoso crescimento nos últimos anos. Muitos estudos foram realizados, porém, em nossas condições, poucas informações foram reunidas, especialmente sob condições de treinamentos físicos homogêneos, quanto à intensidade e duração em eqüinos montados, já que a grande maioria das pesquisas são realizadas em esteira rolante ou durante provas oficiais, onde a homogeneidade do condicionamento é perdida.

O exercício de enduro tem como conseqüência marcante, a perda de fluidos corporais decorrentes da sudorese que está intimamente relacionada com a manutenção da temperatura corpórea do animal. A sudorese prolongada resulta em perdas de fluidos e eletrólitos dos compartimentos intra e extracelulares (Rose et al., 1979; Carlson, 1975; Hodgson et al., 1994). Tomando como referência as perdas de peso corporal durante esforço de baixa intensidade e longa duração, estima-se que um cavalo perde, por hora, entre 10 e 15 litros de suor (Carlson, 1975), contendo grandes concentrações de eletrólitos (Kerr e Snow, 1982; Carlson, 1983; Rose et al., 1990). O sucesso nesta atividade requer animais bem condicionados, uma vez que trabalham no limite de sua capacidade física. Um dos principais desafios à realização de exercício prolongado é a fadiga, que ocorre principalmente pelo

\footnotetext{
* Pós-graduandos da FCAV/UNESP - Jaboticabal, SP

** Prof. Adjunto do Depto. de Morfologia e Fisiologia Animal (FCAV/UNESP-Jaboticabal)

${ }^{* * *}$ Prof. Ass. Dr. Depto. de Clínica e Cirurgia Veterinária - FCAV/UNESP-Jaboticabal. End: Via de Acesso Prof. Paulo Donato Castellane, s/n, CEP 14884-900, Jaboticabal, SP. Email: jlacerda@fcav.unesp.br
} 
esgotamento de líquidos e eletrólitos através da sudação (Schott e Hinchcliff, 1993). O cansaço físico também ocorre em conseqüência de outras alterações, como esgotamento das reservas de glicogênio (Flamínio et al., 1996) ou acúmulo de amônia (Lacerda Neto e Marques, 1999). No presente trabalho estudou-se o efeito do exercício de baixa intensidade e média duração em eqüinos treinados de forma similar e posteriormente submetidos à prova de $40 \mathrm{~km}$ de extensão, sobre algumas variáveis bioquímicas acompanhando-se os animais até 48 horas após a conclusão da prova.

\section{Material e métodos}

Doze fêmeas eqüinas hígidas, entre quatro e 12 anos de idade, das raças Mangalarga e Árabe, utilizadas anteriormente para reprodução, foram introduzidas em programa de treinamento físico para participação em provas de enduro na Faculdade de Ciências Agrárias e Veterinárias (FCAV) da Universidade Estadual Paulista - UNESP, Campus de Jaboticabal. Após um período de 15 dias de adaptação ao alimento, exclusivamente peletizado, iniciou-se o condicionamento físico. Os animais foram treinados (montados) durante seis semanas, em dias alternados, percorrendo trilhas de 9.600 e 12.400 metros em velocidade de 7,5 e 13,5 km/h, respectivamente. Ao final deste período foi realizado um exercício teste (ET), num percurso de $40 \mathrm{~km}$, dividido em dois segmentos de $20 \mathrm{~km}$. Avaliações da freqüência cardíaca foram realizadas antes do início da prova, com os animais em repouso, e 30 minutos após o exercício. As amostras de sangue foram coletadas através de venopunção da jugular antes de iniciar-se o ET, imediatamente após a chegada e 30 minutos, 6, 24 e 48 horas após. As amostras de sangue foram depositadas em tubos sem anticoagulante, para as determinações séricas de proteínas totais, albumina, uréia, creatinina, sódio, potássio, creatina quinase (CK) e aspartato aminotransferase (AST). As dosagens de glicose e amônia foram realizadas em plasma após colheita de sangue em tubos contendo fluoreto de sódio e EDTA, respectivamente. As amostras de plasma e soro sanguíneo foram obtidas após centrifugação (3.000 rpm) e a seguir, foram conservadas em freezer a $-18^{\circ} \mathrm{C}$, até o momento dos exames. As proteínas plasmáticas totais foram determinadas por refratometria ${ }^{1}$ e a glicose plasmática pelo método da ortotoluidina (Dubowyski, 1962). Para análise de sódio e potássio séricos utilizou-se espectofotômetro de chama $^{2}$ e para dosagem de amônia plasmática, kits³; a leitura foi realizada no espectrofotômetro ultravioleta ${ }^{5}$ com filtro de 340nm.

Os valores das atividades de aspartato aminotransferase (AST) foram determinados pelo método de Reitman e Frankel (1957), através da utilização de kits ${ }^{4}$ e leitura espectrofotométrica pela metodologia cinética UV-IFCC. ${ }^{5}$

Os valores das concentrações de cálcio foram determinados através da utilização de kits. $^{5}$

\footnotetext{
${ }^{1}$ Atago SPR -T2. Atago, Japão

${ }^{2}$ Celm FC 180. Celm. São Paulo, SP

${ }^{3}$ Sigma

${ }^{4}$ Kit Labtest-Diagnóstica - Lagoa Santa Ana, MG

${ }^{5}$ Labquest mod. B10 -2000
}

A concentração de proteína plasmática total foi determinada por refratometria ${ }^{6}$ e a concentração plasmática de fibrinogênio foi obtida pela diferença entre as leituras refratométricas de proteína plasmática total antes e após o aquecimento a $56^{\circ} \mathrm{C}$ em banho termostado, ${ }^{7}$ durante cinco minutos (Blaisdell e Dobds, 1977).

Os valores bioquímicos foram avaliados pelo teste de comparação das médias (teste de Tukey), com nível de significância $p<0,05$.

\section{Resultados}

Elevações na concentração de amônia foram registradas ao final da prova e 30 minutos após. Aumento na concentração de proteínas totais foi observado ao final do percurso e após 30 minutos, retornando aos valores basais após seis horas. Foi registrado aumento na concentração plasmática de glicose após o término do percurso, persistindo até 30 minutos após. Ao final da prova ocorreu diminuição na concentração de potássio, mantendo-se em valores inferiores ao basal até seis horas após a chegada. O retorno à concentração normal ocorreu somente ao completar-se 24 horas do término do trajeto.

Discreta, porém significativa elevação da CK ocorreu ao final do percurso, mantendo-se acima dos valores inicialmente determinados até seis horas após, tendo retornado aos valores basais a partir de 24 horas.

As concentrações do íon sódio e da enzima muscular aspartato aminotransferase (AST) não sofreram alterações significativas no decorrer da prova e após. Não foram observadas alterações dignas de nota nas concentrações de albumina, fibrinogênio, uréia e creatinina, cujos valores permaneceram estáveis. As concentrações médias \pm EPM das variáveis bioquímicas analisadas estão relacionadas na Tabela 1 .

\section{Discussão e conclusão}

A glicose constitui uma importante fonte de energia para a fibra muscular. O metabolismo anaeróbico de glicose representa um importante e rápido mecanismo de geração de energia, embora seja de baixa produção. Vários fatores regulam a atividade glicolítica, como a disponibilidade de oxigênio e as concentrações de ATP/ADP. Diminuições na relação ATP/ADP estimulam a glicólise anaeróbica aumentando até 100 vezes a produção de moléculas de piruvato. Em exercícios de intensidades baixa ou moderada, a grande maioria do piruvato produzido penetra na mitocôndria e participa do ciclo de Krebs. Similarmente, a beta oxidação será estimulada para fornecer energia por mecanismo aeróbico. Entretanto, conforme se aumenta a intensidade do exercício, atinge-se um ponto no qual uma quantidade insuficiente de oxigênio está disponível para a fosforilação oxidativa e uma proporção de NADH é reoxidada, via piruvato, sendo metabolizada a lactato. À medida que a intensidade do exercício aumenta, uma maior quan-

${ }^{6}$ Atago T2 -NE
${ }^{7}$ Cientec 
Tabela 1 - São Paulo: UNESP-Jaboticabal, 2003. Média \pm EPM de parâmetros bioquímicos determinados em eqüinos submetidos a prova de resistência de $40 \mathrm{~km}$ de extensão, ao repouso (basal), a chegada e após $0,5,6,24$ e 48 horas.

\begin{tabular}{|c|c|c|c|c|c|c|}
\hline \multirow[b]{2}{*}{ Variáveis } & \multirow[b]{2}{*}{ Basal } & \multirow[b]{2}{*}{ Chegada } & \multicolumn{4}{|c|}{ Após a chegada (horas) } \\
\hline & & & 0,5 & 6 & 24 & 48 \\
\hline Glicose (mg/dl) & $86,9 \pm 15$ & $103,0 \pm 36$ & $116,3 \pm 34$ & -- & -- & -- \\
\hline Amônia $(\mu \mathrm{g} / \mathrm{dl})$ & $29 \pm 5,6^{a}$ & $76,7 \pm 18^{b}$ & $60,1 \pm 15^{b}$ & -- & -- & -- \\
\hline Proteínas Totais (g/dl) & $7,5 \pm 0,3^{a}$ & $8,5 \pm 0,4^{b}$ & $8,5 \pm 0,4^{b}$ & $7,9 \pm 0,4^{a, b}$ & $7,7 \pm 4,4^{\mathrm{a}, \mathrm{b}}$ & $6,9 \pm 0,3^{a}$ \\
\hline Albumina (g/dl) & $2,8 \pm 0,2$ & $3,2 \pm 0,3$ & $3,2 \pm 0,2$ & $3,0 \pm 0,3$ & $2,7 \pm 0,2$ & $2,7 \pm 0,2$ \\
\hline Fibrinogênio (g/dl) & $0,7 \pm 0,1$ & $0,8 \pm 0,2$ & $0,7 \pm 0,1$ & $0,6 \pm 0,1$ & $0,6 \pm 0,1$ & $0,4 \pm 0,2$ \\
\hline Uréia (mg/dl) & $36,1 \pm 2,3$ & $44,6 \pm 3,1$ & $48,9 \pm 5,3$ & $54,9 \pm 5,8$ & $49,8 \pm 5,5$ & $43,4 \pm 3,3$ \\
\hline Creatinina (mg/dl) & $1,47 \pm 0,3$ & $1,95 \pm 0,6$ & $1,93 \pm 0,6$ & $1,77 \pm 0,4$ & $1,46 \pm 0,2$ & $1,19 \pm 0,2$ \\
\hline Sódio (mmol/l) & $136 \pm 2,6$ & $143 \pm 3,5$ & $145 \pm 6,2$ & $137 \pm 4,8$ & $140 \pm 6,7$ & $140 \pm 3,6$ \\
\hline Potássio (mmol/l) & $4,1 \pm 0,2^{a}$ & $3,3 \pm 0,2^{b}$ & $3,0 \pm 0,2^{b}$ & $3,4 \pm 0,4^{b, c}$ & $4,1 \pm 0,5^{a, c}$ & $3,8 \pm 0,2^{a, c}$ \\
\hline CK (U/I) & $53 \pm 10^{a}$ & $96 \pm 19^{b}$ & $129 \pm 34^{b}$ & $189 \pm 62^{b}$ & $50 \pm 26^{a, c}$ & $26 \pm 11^{c}$ \\
\hline AST (U/I) & $119 \pm 26$ & $139 \pm 26$ & $139 \pm 39$ & $131 \pm 38$ & $130 \pm 26$ & $112 \pm 25$ \\
\hline
\end{tabular}

CK: creatina quinase, AST: aspartato aminotransferase

Os valores referentes as concentrações de glicose e amônia nos tempos 6,24 e 48 horas após a chegada não foram dosados, pois as amostras foram perdidas.

tidade de lactato é produzida e uma maior proporção de energia é suprida pelas vias anaeróbicas (Eaton, 1994). A concentração plasmática de glicose se apresentou dentro dos valores de referência no decorrer do enduro, assim como observado por Ramón et al. (2000) em eqüinos que realizaram um percurso de $42 \mathrm{~km}$. Embora, aparentemente, a glicose não seja a principal fonte de energia durante exercício prolongado, nos animais bem condicionados sua mobilização é um fato marcante, como pode ser atestado neste trabalho, apesar das elevações observadas na concentração dessa variável não terem sido significativas.

Após a realização de atividade física intensa (Miller e Lawrence, 1986), foi detectado aumento na concentração plasmática de amônia em eqüinos. Durante o exercício a amônia é produzida no músculo esquelético por deaminação da adenosina monofosfato (Buono et al., 1984) e sua elevação se dá também durante exercício de baixa intensidade e longa duração, como registrado na presente pesquisa, assim como em outros trabalhos (Lacerda Neto e Marques, 1999). Uma grande parcela da energia gerada para o trabalho muscular é transformada em calor, cuja dissipação ocorre, principalmente nos eqüinos, através da sudação. Aumentos séricos das proteínas totais refletem ocorrência de hemoconcentração, a qual se mantém ainda por algumas horas após o término do exercício, mesmo quando o animal ingere grandes quantidades de água. Neste trabalho, o retorno aos valores basais das proteínas totais ocorreu no intervalo entre 0,5 e 6 horas após o término do exercício teste, o que demonstra a rapidez com que se restabelece o equilíbrio hídrico. Carlson (1983) concluiu que a desidratação severa durante o exercício de enduro causa uma marcante elevação na concentração de proteína plasmática. Da mesma forma constatou Teixeira Neto (2002), em eqüinos submetidos à prova de $60 \mathrm{~km}$. Não foram notadas alterações marcantes na concentração de sódio plasmático em nosso estudo, bem como no estudo de Knochel (1980), apesar de grandes perdas no suor. Tal fato corrobora outros estudos que verificaram que a concentração plasmática de sódio permanece relativamente normal porque um volume equivalente de fluido é perdido (Rose, 1990; Snow et al., 1982; Carlson, 1983; Ecker e Lindinger, 1995; Ramón et al., 2000).

Notou-se um decréscimo dos valores da concentração de íons potássio. Conforme observado por Ramón et al. (2000) e Ecker e Lindinger (1995), que concluiu que a desidratação aumenta a reabsorção renal de sódio às custas da excreção de potássio e íons hidrogênio, contribuindo para uma hipocalemia e alcalose metabólica. Teixeira Neto (2002) encontrou resultados semelhantes em eqüinos submetidos à prova de $60 \mathrm{~km}$. Entretanto, a regulação de alguns íons, como o potássio, cuja diminuição ao final da atividade física ocorreu tanto pelas perdas através da sudação como pela diluição promovida pela ingestão de grandes volumes de água, demora algumas horas a mais (Lacerda Neto e Marques, 1999). Com relação aos resultados referentes à atividade da enzima muscular creatina quinase (CK), observou-se uma discreta, porém significativa, elevação ocorrida após o exercício, o que demonstra aumento do esforço muscular; porém, na intensidade reportada, não está associada à lesão muscular, pois ocorreu dentro dos limites normais de referência (Jones 1989). Quanto à atividade da enzima muscular aspartato aminotransferase (AST), tais valores não revelaram qualquer variação significativa. Tal fato demonstra que os esforços aos quais os animais foram submetidos neste estudo, não foram suficientes para causar qualquer tipo de dano muscular, indicado pela mensuração da atividade desta enzima, visto que, somente valores maiores que $550 \mathrm{UI} / \mathrm{L}$ poderiam estar correlacionados com um certo grau de lesão muscular (Jones, 1989). 
Embora, a princípio, possa-se considerar baixa a intensidade utilizada nesse treinamento, os resultados obtidos demonstraram que o esforço imposto no ET foi adequado, uma vez que as alterações observadas foram mínimas. Foram registrados aumentos na resistência física quando se trabaIhou com eqüinos em intensidades mais baixas, porém por períodos mais prolongados (Lindner et al., 2001).

Os resultados aferidos neste trabalho permitem concluir que os animais utilizados neste estudo demonstraram algumas variações nas concentrações das variáveis bioquímicas es-

\section{Referências}

BUONO, M. J.; CLANCY, T. R.; COOK, J. R. Blood lactate and ammonium ion accumulation during graded exercise in humans. J Appl Physiol Respir Envirom Exer Physiol, v. 57, p. 135-139, 1984.

CARLSON, G. P. Hematologic alterations in endurance-trained horses. In: INTERNATIONALSYMPOSIUM ONEQUINE HEMATOLOGY, 1., 1975, Lansin, Michigan. Proceedings..., 1975. p. 473.

CARLSON, G. P. Thermoregulation and fluid balance in the exercising horse. In: SNOW, D. H.; PERSON, S. G. B.; ROSE, R .J. Equine exercise physiology. Cambridge: Granta Editions, 1983, p. 275-309.

EATON, M. D. Energetics and performance. In: HODGSON, D. R.; ROSE, $\mathrm{R}$. J. The atletic horse: principles and practice of equine sports medicine. Philadelphia: WB Saunders. 1994. p. 49-62.

ECKER, G. L.; LINDINGER, M. I. Effects of terrain, speed, temperature and distance on water and ion losses. Equine Vet. J. Suppl., v. 18, p. 298-395, 1995.

FLAMÍNIO, M. J. B. F.; GAUGHAN, E. M.; GILLESPIE, J. R. Exercise intolerance in endurance horses. Vet. Clin. North Am. Equine Pract., v. 12, p. 565-580, 1996.

HODGSON, D. R.; DAVIS, R. E.; McCONAGHY, F. F. Thermoregulation in the horse in response to exercise. Br. Vet. J., v. 150, p. 219-235, 1994.

JONES, W. E. Equine sports medicine. Philadelphia: Lea e Febiger, 1989. KERR, M. G.; SNOW, D. H. Alterations in plasma protein and electrolytes in horses following the feeding of hay. Vet. Rec., v. 110, p. 538-540, 1982. KNOCHEL, J. P. Clinical physiology of heat exposure. In: MAXWELE, M. H.; KLEENAN, C. R. Clinical disorders of fluid and electrolyte metabolism.1980, New York: McGraw-Hill, p.1519. tudadas durante e após o enduro. No entanto tais valores permaneceram dentro dos limites fisiológicos para a espécie eqüina indicando que o teste de esforço realizado não foi capaz de determinar fadiga nesses animais. Estudos de curso mais prolongado e detalhado devem ser realizados para determinar com maior acurácia os mecanismos de regulação hidro-salina. Muitos fatos ainda precisam ser esclarecidos para uma melhor compreensão das respostas fisiológicas que ocorrem no eqüino submetido ao exercício de longa duração.

LACERDANETO, J. C.; MARQUES, L. C. Utilização de parâmetros clínicos e bioquímicos na avaliação de eqüinos submetidos a exercício de baixa intensidade e média duração. Veterinária Notícia, v. 5, p. 77-82, 1999.

LINDNER et al. Efecto de entrenamiento, conducido mediante la concentración de láctato sanguíneo, sobre ultraestructura del músculo glúteo medio. Anais do CICADE, Argentina, 2001.

MILLER, P. A.; LAWRENCE, L. M. Changes in equine metabolic characteristics due to exercise fatigue. Am. J. Vet. Res., v. 47, p. 4150, 1986.

RAMÓN, M. P. et al. Cambios sanguineos y sudorales en equinos sometidos a carreras de resistencia. Avances Cien. Vet., v. 15, n. 1-2, p. 19-30, 2000.

ROSE, R. J.; HENDRICKSON, D. K.; KNIGHT, P. K. Clinical exercise testing in the normal Thoroughbred racehorse. Aust. Vet. J., v. 67, p. 345, 1990.

ROSE, R. J.; ILKIW, J. E.; MARTIN, I. C. A. Blood-gas, acid-base and haematological values in horses during an endurance ride. Equine Vet. J., v. 11, p. 56-59, 1979.

SCHOTT, H. C.; HINCHCLIFF, K. W. Fluids, electrolytes, and bicarbonate. Vet. Clin. North Am. Equine Pract., v. 9, p. 577-604, 1993.

SNOW, D. H. et al. Alterations in blood, sweat, urine and muscle composition during prolonged exercise in the horse. Vet. Rec., v. 110, p. 377-384, 1982.

TEIXEIRA NETO, A. R. Efeitos da reposição eletrolítica sobre variáveis fisiológicas de cavalos em provas de enduro de 30 e 60 km de distância. 2002. 92 p. Dissertação (Mestrado) - Faculdade de Ciências Agrárias e Veterinárias - UNESP- Jaboticabal, 2002. 